\title{
Wind Climatology for Alaska: Historical and Future
}

\author{
Kyle Redilla' ${ }^{1}$, Sarah T. Pearl'2, Peter A. Bieniek ${ }^{3}$, John E. Walsh ${ }^{1}$ \\ ${ }^{1}$ Alaska Center for Climate Assessment and Policy, University of Alaska, Fairbanks, AK, USA \\ ${ }^{2}$ Dartmouth College, Hanover, NH, USA \\ ${ }^{3}$ International Arctic Research Center, University of Alaska, Fairbanks, AK, USA \\ Email: jewalsh@alaska.edu
}

How to cite this paper: Redilla, K., Pearl, S.T., Bieniek, P.A. and Walsh, J.E. (2019) Wind Climatology for Alaska: Historical and Future. Atmospheric and Climate Sciences, 9, 683-702.

https://doi.org/10.4236/acs.2019.94042

Received: September 20, 2019

Accepted: October 28, 2019

Published: October 31, 2019

Copyright $\odot 2019$ by author(s) and Scientific Research Publishing Inc. This work is licensed under the Creative Commons Attribution International License (CC BY 4.0).

http://creativecommons.org/licenses/by/4.0/

\begin{abstract}
Wind is a climate variable with major impacts on humans, ecosystems and infrastructure, especially in coastal regions with cold climates. Climate-related changes in high-wind events therefore have major implications for high-latitude residents, yet there has heretofore been no systematic evaluation of such changes in a framework spanning historical and future timeframes. In this study, hourly winds from surface station reports and from dynamical downscaling of winds simulated by two different global climate models have been synthesized into historical and future wind climatologies for Alaska. Quantile mapping procedures are used to calibrate wind simulations driven by an atmospheric reanalysis, and the calibrated winds are then used to bias-adjust the full distributions of historical and future winds downscaled from the global climate models. In the resulting climatologies, winds are generally stronger at coastal and offshore (island) locations than at interior sites, where calm conditions are frequent in winter. The season of peak wind speed varies from winter in the coastal and offshore locations to summer in interior areas. High-wind events determined from the hourly data are most frequent during winter at coastal locations. Projected changes for the late $21^{\text {st }}$ century are statistically significant at many locations, and they show a qualitatively similar seasonality in the output from the two models: an increase of mean wind speeds in the cold season and a decrease of mean wind speeds in the warm season. High-wind events are projected by both models to become more frequent in the northern and western Alaska coastal regions, which are precisely the regions in which the protective sea ice cover has decreased (and is projected to decrease further), pointing to increased risks of coastal flooding and erosion.
\end{abstract}

\section{Keywords}

Wind, Climatology, Alaska, Climate Impacts 


\section{Introduction}

Wind is a climate variable with major impacts on humans and the biosphere. For example, strong winds damage infrastructure, impact outdoor activities (e.g., transportation, construction), and affect human comfort. Wind-driven waves are responsible for coastal flooding and erosion, as well as damage to vegetation over land. Wind also is a key determinant of the surface fluxes of heat and moisture, making it a key variable in interactions between the atmosphere and the surface of the ocean and land. Finally, wind is an increasingly important source of renewable energy, an application that provides additional motivation for determinations of wind climatologies and their potential changes.

While temperature and precipitation are the subjects of many climatological studies, there have been relatively few studies of high-latitude winds in a climatological framework, especially in the context of climate change. The few such studies have drawn upon a variety of sources of information on high-latitude winds. For example, [1] made use of wind observations from Barrow in northern Alaska to assess the impacts of extreme wind events at a single location. [2] used winds obtained from several reanalysis products and a regional climate model to map the median and $99^{\text {th }}$ percentile wind speeds across the Arctic, with an emphasis on the comparison between the regional model simulations and the reanalyses. The North American Regional Reanalysis formed the basis of an evaluation of the wind field climatology, changes and extremes over the BeaufortChukchi Seas and North Slope of Alaska [3]. [4] presented a wind climatology based on the Coupled Forecast System Reanalysis (CFSR), together with the associated climatology of wind-driven waves.

As the studies highlighted above indicate, most high-latitude wind studies have been based on reanalysis products or model simulations. Few studies have systematically examined station observations, primarily because the network of high-latitude stations that report winds is sparse. Moreover, the longer-term historical records of surface winds are subject to heterogeneities, as discussed in the following sections. [5] and [6] constructed station-based climatologies of near-surface winds over parts of Canada, with particular attention to the homogenization issue in the latter study. More recently, [7] evaluated observations of wind from 19 stations over Alaska with an application to wind energy generation. Although [7] evaluated temporal changes in wind speed at the observing stations, heterogeneities in the station record were not addressed.

While there have been relatively few climatological studies of high-latitude winds and their trends, there have been essentially no attempts to assess future changes in high-latitude winds. Little such work has been done even for middle latitudes, although one such study is [8]'s evaluation of past and future wind climates over the contiguous United States. The projections obtained in this study were based on five regional climate models run at $50 \mathrm{~km}$ resolution. The results indicated a future (2041-2062) decrease in the $90^{\text {th }}$ and $95^{\text {th }}$-percentile wind speeds, although not in the highest wind speeds. One example of a wind 
projection for Alaska is [9]'s downscaling of winds for a near-future (2016-2032) time slice in a case study targeting wind energy at a site near Juneau.

There has yet to be a study of high-latitude wind speeds in which changes are systematically evaluated for a high-latitude region over both historical and future periods. Moreover, there have been no attempts to date to use homogenized observational data to calibrate model simulations used to obtain projections of future winds. The present study describes a synthesis of surface station observations and model output in order to optimize wind climatologies for various applications over a high-latitude area, Alaska, where wind is an especially highimpact variable. In addition to the more geographically widespread impacts noted above, impacts in cold-climate regions such as Alaska include the redistribution of snow and exacerbation of extreme wind chill effects on humans and animals. Given the importance of possible changes in winds and their climatological characteristics, the present study targets climatologies of near-surface winds over historical and future time periods.

Because we wish to compare present and future wind climatologies, projections from climate models are necessary. It is well known, however, that climate model simulations contain systematic errors. For this reason, we use observational data to calibrate model output. This synthesis of observational data and model output provides a database on near-surface winds spanning historical and future time slices, thereby enabling an assessment of differences in the wind climatologies over the two timeframes.

Wind climatologies are often presented in terms of mean or median wind speeds. In this study, we work with the full distributions of wind speeds in order to allow a focus on high-wind events, which are associated with the greatest impacts. In particular, we document changes in the frequencies of high wind events at various locations over recent decades and changes from the recent decades to a future (late $21^{\text {st }}$ century) time period.

In summary, the present study differs from previous work in several ways. First, it represents a fusion of observational data and model-derived output to optimize the wind information. The observational data are quality-controlled by a homogenization procedure. Second, it presents future wind climatologies for comparison with climatologies of the recent historical period. Third, it specifically addresses the future changes in high-wind events as well as changes in mean wind speeds.

Section 2 describes the observational data and the model simulations of winds over Alaska. We then document the data-model fusion process, which is based on a quantile mapping procedure carried out in two steps. This methodological description is followed in Section 3 by a presentation of the results, which are presented in two subsections: 1) the seasonal cycle and spatial variability of the present-day (historical) climatology, including the climatological frequency of high-wind events in the historical time period, and 2) projected changes in the climatology of mean winds and frequencies of high-wind events in the late- $21^{\text {st }}$ century. 


\section{Sources of Data}

\subsection{Observations}

The primary observational database consists of hourly wind reports from $67 \mathrm{ob}-$ serving sites distributed throughout Alaska (Figure 1). Nearly all the sites are at airports. Over the last two decades, most stations have been automated and are now part of either the ASOS (Automated Surface Observing System) network or the AWOS (Automated Weather Observing System) network operated by the Federal Aviation Administration. The hourly reports consist of a wind speed (knots, archived as miles per hour) and a wind direction (to the nearest $10 \mathrm{de}-$ grees). The standard level for wind measurements is 10 meters, although the instrument heights have varied at some locations, requiring adjustments of the wind speeds (see below). For inclusion in the historical climatology, a station was required to have reported four or more hourly winds on at least $75 \%$ of the days in the 35-year period, 1980-2014.

Because the instruments, their heights above the surface (now 10 meters), or their precise locations have undergone changes at some observing sites since 1980 , the data from all stations were subjected to homogeneity tests. If the wind speeds at a station showed a statistically significant change from one portion of the record to the next, the data prior to the change were adjusted so that its distribution matched that of the observations subsequent to the change. The data from 28 of the 67 stations required this type of adjustment. Four of the stations displayed two discontinuities, in which case the quantile mapping adjustment to the later period was applied twice.

The adjustment procedure used here is referred to as quantile mapping. In the quantile mapping procedure, the data in each sample are placed into quantiles based on a ranking of the values from smallest to largest. The term "quantile" refers to a subset of the distribution; if the total number of quantiles were chosen to be 100 , the quantiles would be equivalent to percentiles. In the quantile mapping procedure used here, the number $(\mathrm{N})$ of quantiles is equal to the smaller of the two sample sizes, so that each quantile contains one member of the smaller sample. The larger sample is also ranked and placed into the $\mathrm{N}$ quantiles, each of which can contain more than one data point. A particular quantile will therefore have two values, one (possibly an average of more than one wind observation)

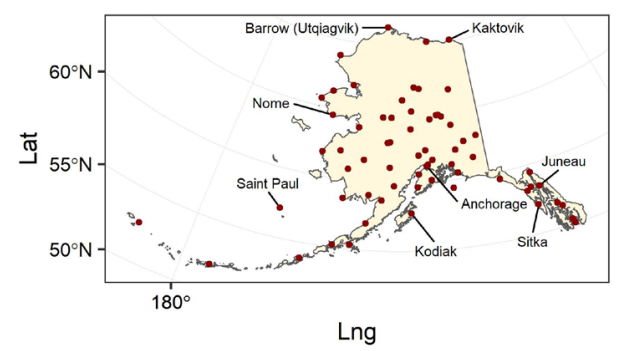

Figure 1. Stations for which hourly observations were used in constructing the wind climatology for Alaska. Place names denote stations for which climatology of high-wind events was evaluated. 
from the distribution prior to the change and a corresponding value from the distribution following the change. The difference between these two values is an adjustment factor that is added to the biased value obtained prior to the instrument or site upgrade. The application of this procedure, illustrated in Figure 2, results in two (or three) subsamples having the same mean values and distributions.

Additional quality-control steps included removal of obviously erroneous reports (e.g., wind speeds exceeding $100 \mathrm{mph}$ ) and the removal of short-duration $(<4$ hours) spikes in which an hourly wind speed was at least $30 \mathrm{mph}$ greater than in immediately preceding and subsequent hours.

\subsection{Model Output}

A second source of hourly wind information was a set of regional climate model simulations for a domain encompassing all of Alaska. The simulations were performed with the Advanced Research version of the Weather Research and Forecasting (WRF) model [10] and used an optimized configuration of the WRF model physical parameterizations for Alaska as described by [11]. The simulations covered a domain with $262 \times 262$ grid points that encompassed all of Alaska and portions of far eastern Russia and northern Canada at 20-km spatial resolution with 49 vertical model levels.

Lateral forcing and surface boundary conditions (sea surface temperature, sea ice) were obtained from several sources, resulting in a suite of simulations of the historical and future time periods. Table 1 summarizes the various simulations, including the time period of the simulations and the Greenhouse Gas (GHG) forcing.

The simulations represent downscaling to achieve finer resolution of coarser-resolution atmospheric analyses or model output. As described by [13], the downscaling simulations were performed in 54-hour increments. The model was reinitialized (to either the ERA-Interim reanalysis or to a global climate model)

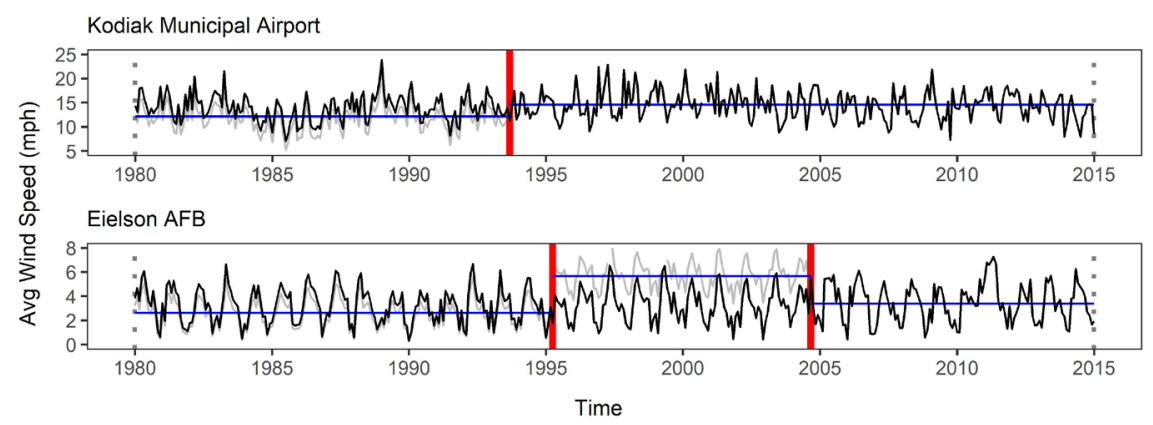

Figure 2. Sample time series of monthly wind speeds illustrating adjustment for discontinuities at Kodiak (upper panel) and Eielson Air Force Base (lower panel). Vertical red bars denote discontinuities prior to quantile-mapping adjustments; horizontal blue lines are sub-period means. Lighter gray lines are values prior to adjustment, solid black lines are corresponding values after adjustments. Original wind speed observations were obtained from Iowa Environmental Mesonet, https://mesonet.agron.iastate.edu/request/download.phtml. 
Table 1. Summary of model simulations.

\begin{tabular}{ccc}
\hline & Boundary conditions & External forcing \\
\hline Historical simulations & & \\
$1980-2014$ & ERA-Interim reanalysis [12] & historical GHG \\
$1980-2005$ & GFDL CM3 global climate model & historical GHG \\
$1980-2005$ & CCSM4 global climate model & historical GHG \\
\hline Future simulations & & \\
$2006-2100$ & GFDL CM3 global climate model & RCP 8.5 scenario \\
$2006-2100$ & CCSM4 global climate model & RCP 8.5 scenario \\
\hline
\end{tabular}

every two days for a subsequent 54-hour simulation, from which the first 6 hours of spin-up time data were discarded. These spin-up data could be discarded because they overlap with the last 6 hours of the previous 54-hour integration. The output from the remaining 48 hours of each integration was combined together to form the final downscaled product. Because the WRF model is reinitialized every 2 days, parameters such as atmospheric moisture and energy are not precisely conserved over the entire period of the downscaling as in a continuous model run. However, the WRF simulation is constrained to the larger-scale driving fields by a nudging procedure in addition to the reinitialization every 48 hours. The hourly output from each simulation was saved. This output included the 10-meter winds, which were used in this study.

The WRF model's performance over Alaska when forced by the ERA-Interim reanalysis has been described by [13]. Relative to the ERA-Interim reanalysis, the WRF-simulation improves the spatial depictions of temperature and precipitation. The effects of the improved resolution are especially apparent in the mountain areas and coastlines that are prominent features of Alaska's geography. In particular, lower temperatures and higher upslope precipitation amounts are apparent in the mountainous areas in the higher-resolution simulations, while coastal contrasts are sharpened (Figures 2-4 of [13]). Winds also show sharper coastal gradients, consistent with contrasts in surface roughness, although the quantile mapping employed here serves to adjust the WRF-derived winds to agree with observations regardless of the magnitude of any systematic errors. Finally, the ERA-Interim reanalysis used to boundary-force the WRF model and to re-initialize it has been shown to be one of the most realistic atmospheric reanalyses for capturing Alaska's climate [14].

The model simulations summarized in Table 1 enable us to expand the information provided by the surface observing stations in several ways. First, the availability of model winds at all time steps allows for in-filling of missing observations. Second, because the model simulations extend through the year 2100, they enable evaluations of projected changes from the historical to the future time periods. Finally, the model simulations provide output on a regular grid of points covering all of Alaska and the adjacent seas. However, model simulations 
contain systematic errors that require adjustment before the model-derived winds can be considered compatible with the observed winds. In order to establish this compatibility, we adjust the modeled winds so that their distribution over the historical period matches that of the observed winds at each observational site. The adjustment is achieved by a quantile-mapping procedure such as that described above. In this case, all observed wind speeds from an observing station are assigned quantiles. The model's winds from the ERA-forced simulation are then binned into the same quantiles, and the difference between each pair of corresponding quantile values is used to "correct" the modeled winds in that quantile. In this way, the ERA-forced simulation provides a complete (no missing hours) history of winds over the historical time period, and the distribution matches that of the available station data. Figure 3(a) shows an example of the quantile mapping of the ERA-driven model output for a location at which the model's wind speeds are generally greater than the observed. In this case, the quantile mapping shifts the wind distribution to the left, i.e., towards lower wind speeds, to match the observed distribution.

The quantile-mapped ERA-driven WRF wind speeds serve as the basis for our wind analysis because they have the advantage of temporal completeness (i.e., no missing values). As an illustration of this advantage, Figure 4 shows how the ERA-forced model winds correspond with the station (ASOS) measured winds during several high-wind events, three at Nome and three at Barrow. The two sources correspond quite closely, and the gap-filling is apparent in several of the examples. In particular, during the Nome high-wind event of November 2011 (bottom right panel), the anemometer ceased functioning when the winds reached $40 \mathrm{mph}$. The gap-filling based on the model output shows that the winds reached a peak of approximately $60 \mathrm{mph}$ while the anemometer was not operating. More generally, the measured winds show slightly more hour-to-hour variability than do the model-derived winds, consistent with the fact that the latter are averages over $20 \mathrm{~km} \times 20 \mathrm{~km}$ grid cells while the observed values are for single points. Moreover, those single points are almost entirely airport sites. The winds at a relatively flat airport site can easily differ from those over more heterogeneous terrain within the same grid cell. While Figure 3 and Figure 4 support the validity of the model-derived winds, this type of model-data fusion is only possible for locations for which observational data are available. For that reason, we do not present statewide maps or other areal products that would contain unadjusted wind output from the model.

Having established that the adjusted ERA-driven model output closely approximates the actual winds at the observing sites, we use the modeled winds for the historical period to quantile-map the winds obtained from the global climate models, CCSM4 and GFDL's CM3. Specifically, the historical simulations of the CCSM4 and CM3 models are quantile-mapped to the ERA-forced WRF historical winds (1980-2005), and the adjustment factors for each quantile are then applied to the future simulations of the two models (2006-2100). Figure 5 summarizes the quantile mapping adjustments, beginning with the use of the station 


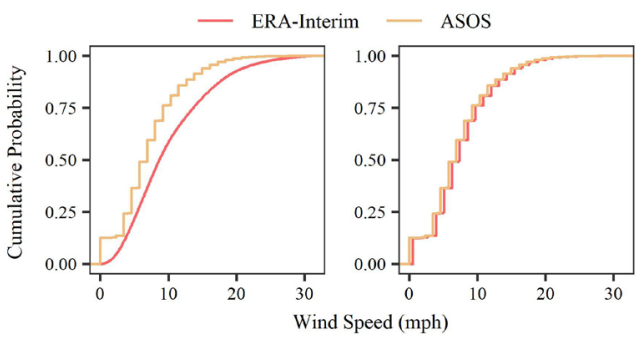

(a)

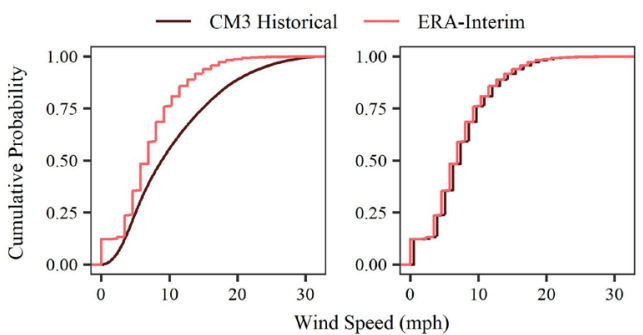

(b)

Figure 3. Examples of cumulative distributions before and after adjustment by quantile mapping. Upper panels show mapping of ERA-Interim values (red line) to corresponding ASOS values (tan line). Lower panel illustrates mapping of CM3 historical distribution (brown line) to ERA-Interim historical distribution for same location (red line). ASOS distributions contain steps because reporting code rounds observed wind speeds to nearest knot. ASOS wind speed observations were obtained from Iowa State University, Iowa Environmental Mesonet, https://mesonet.agron.iastate.edu/request/download.phtml.
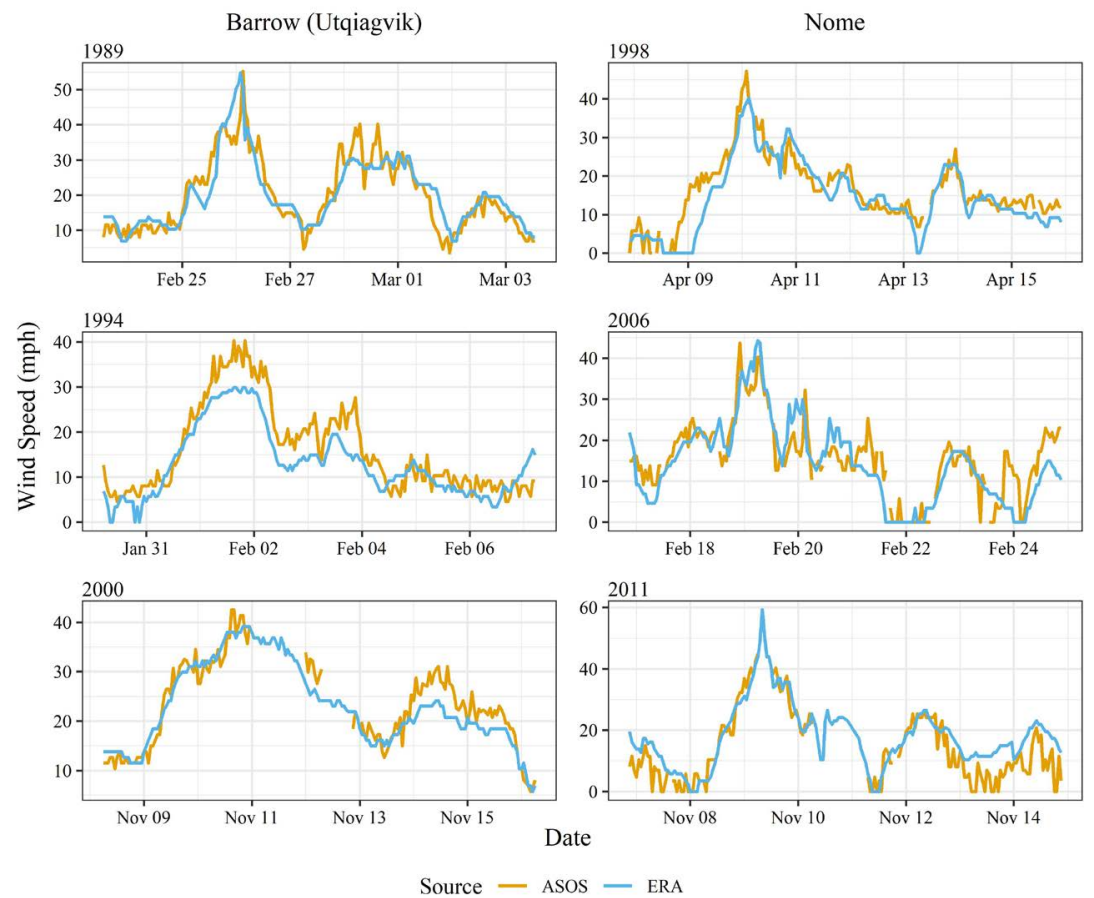

Figure 4. Examples of the correspondence of the station-measured (ASOS) winds (orange lines) and the quantile-mapped winds from the downscaled ERA-Interim reanalysis (blue lines). Panels in left column are high-wind events at Utqiagvik (Barrow), panels in right column are high-wind events at Nome. Duration of each time series is four days. Station observations were obtained from Iowa Environmental Mesonet, https://mesonet.agron.iastate.edu/request/download.phtml. 


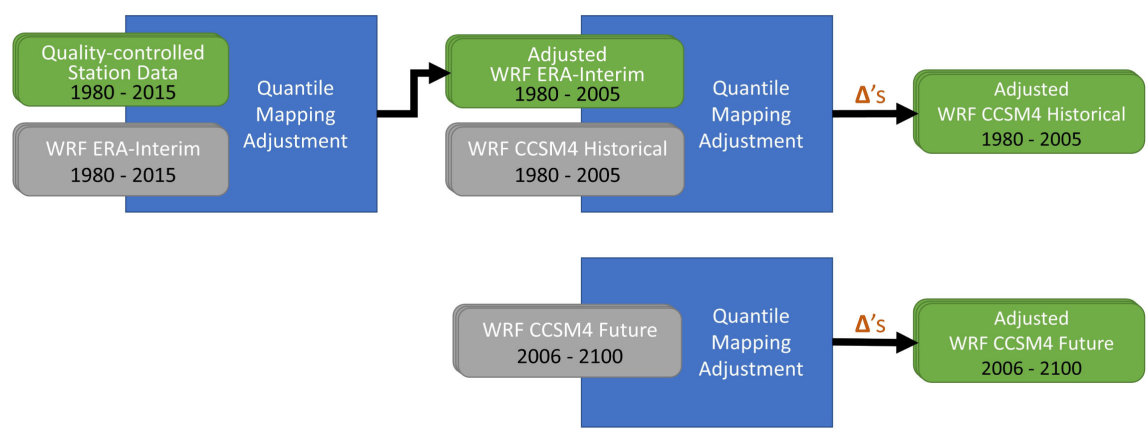

Figure 5. Summary of quantile mapping adjustments applied to the downscaled WRF model output driven by the ERA-Interim reanalysis (left) and the global climate models (right).

data to bias-adjust the ERA-driven historical simulation by the WRF model. For the right-hand portion of Figure 5, the underlying assumption-typically made in applications of the "delta method" of climate model bias adjustment-is that the models' biases are similar in the future and historical simulations. While there can be no proof that this is the case, no superior alternative strategies have emerged for bias adjustment of output for the future. We also note here that the bias adjustment is applied only to the wind speed, not wind direction. For this reason, the results in the following section include directional information only from the ERA reanalysis-driven historical simulation, not from the simulations driven by the global climate models.

The Alaska simulations by the two global climate models, CCSM4 and CM3, have been evaluated in several studies. [15] showed that both models capture the spatial distributions of temperature and precipitation quite realistically, although the CM3 model displays a stronger sensitivity to external (greenhouse gas) forcing. [16] evaluated the sea level pressure fields as well as the temperature and precipitation distributions of these two models as part of a more comprehensive evaluation of 21 global climate models from the Coupled Model Intercomparison Project, Phase 5 (CMIP5). The inclusion of sea level pressure in the evaluation is especially relevant to the present study because the near-surface winds are determined primarily by sea level pressure gradients. CM3 and CCSM4 were among the highest-ranking models for the Alaska domain based on an aggregate (sea level pressure, temperature, precipitation) mean-absolute-error metric: CM3 ranked third and CCSM4 ranked sixth out of 21 models.

\section{Results}

\subsection{Historical Climatology}

We illustrate the results by showing climatological seasonal cycles of wind speed over the historical period (1980-2014). Figure 6 contains a sample of the seasonal cycles, showing that average wind speeds vary from relatively small values at interior stations (Fairbanks, Bettles) to relatively high values at coastal (Barrow) and island (St. Paul, Kodiak) sites. There are also pronounced differences in the 

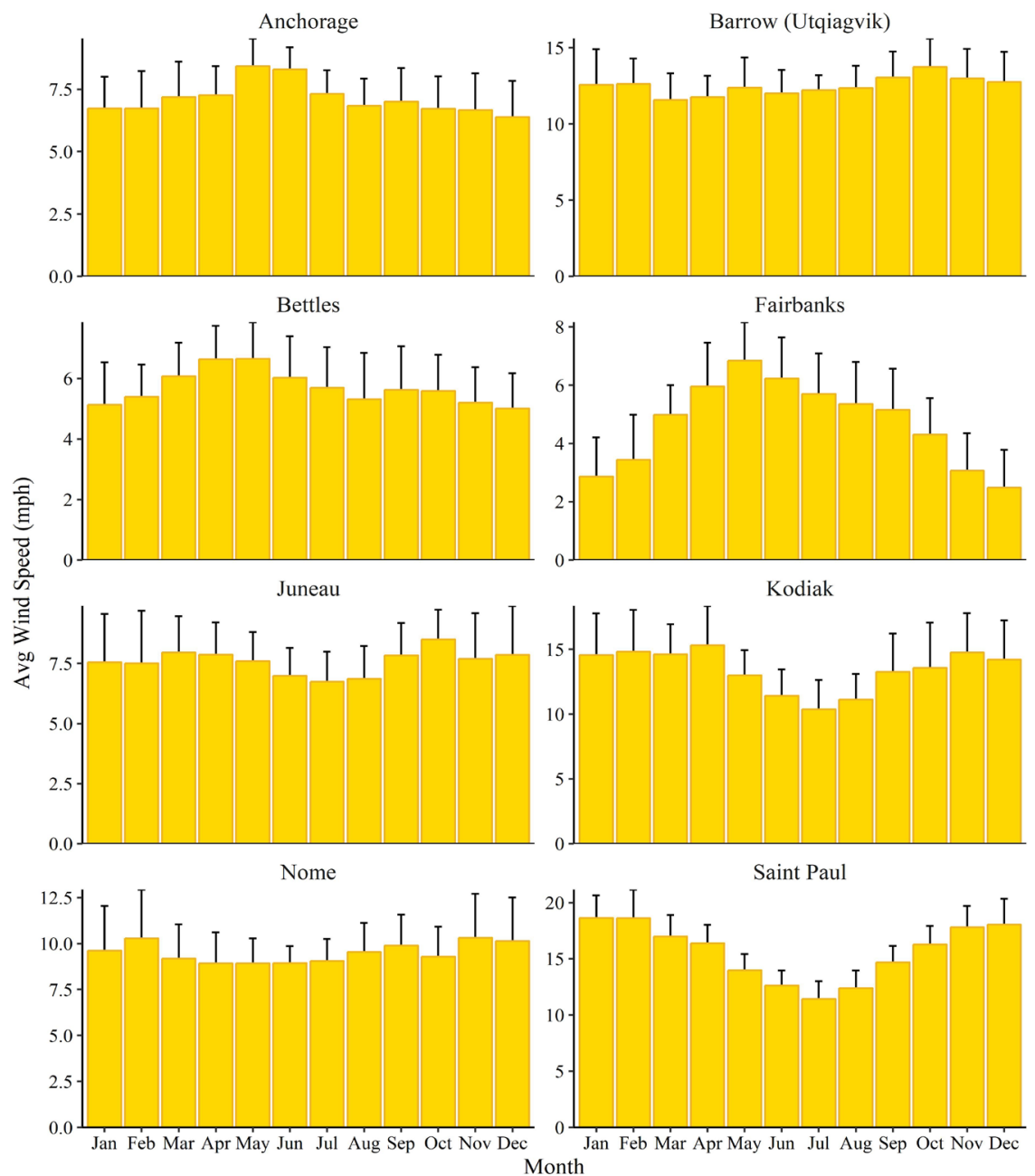

Figure 6. Seasonal cycles of climatological mean wind speeds (mph) over the 1980-2014 historical period at Anchorage, Barrow (Utqiagvik), Bettles, Fairbanks, Juneau, Kodiak, Nome and St. Paul. Whiskers denote standard deviations of monthly values.

seasonality among the locations, as the inland sites such as Fairbanks tend to have maxima in the summer while the coastal and island sites have maxima in the cold season.

Wind direction also varies seasonally at many stations, as illustrated by the monthly wind roses derived from the actual station data. An example for Anchorage is presented in Figure 7. While northerly winds dominate during the winter at Anchorage, winds from the south and southeast are most common during the summer. The frequency of calm conditions (annotation in bottom right of each wind rose) is also substantially higher during the winter than during the summer. Climatological and annual wind roses for all 67 stations are available at a website (http://windtool.accap.uaf.edu), which also provides displays of the climatological monthly wind speeds for each station.

While mean wind speeds and their seasonality are fundamental metrics of a location's wind climatology, the frequency of high-wind events is a wind characteristic associated with the impacts. High-wind events are especially hazardous 


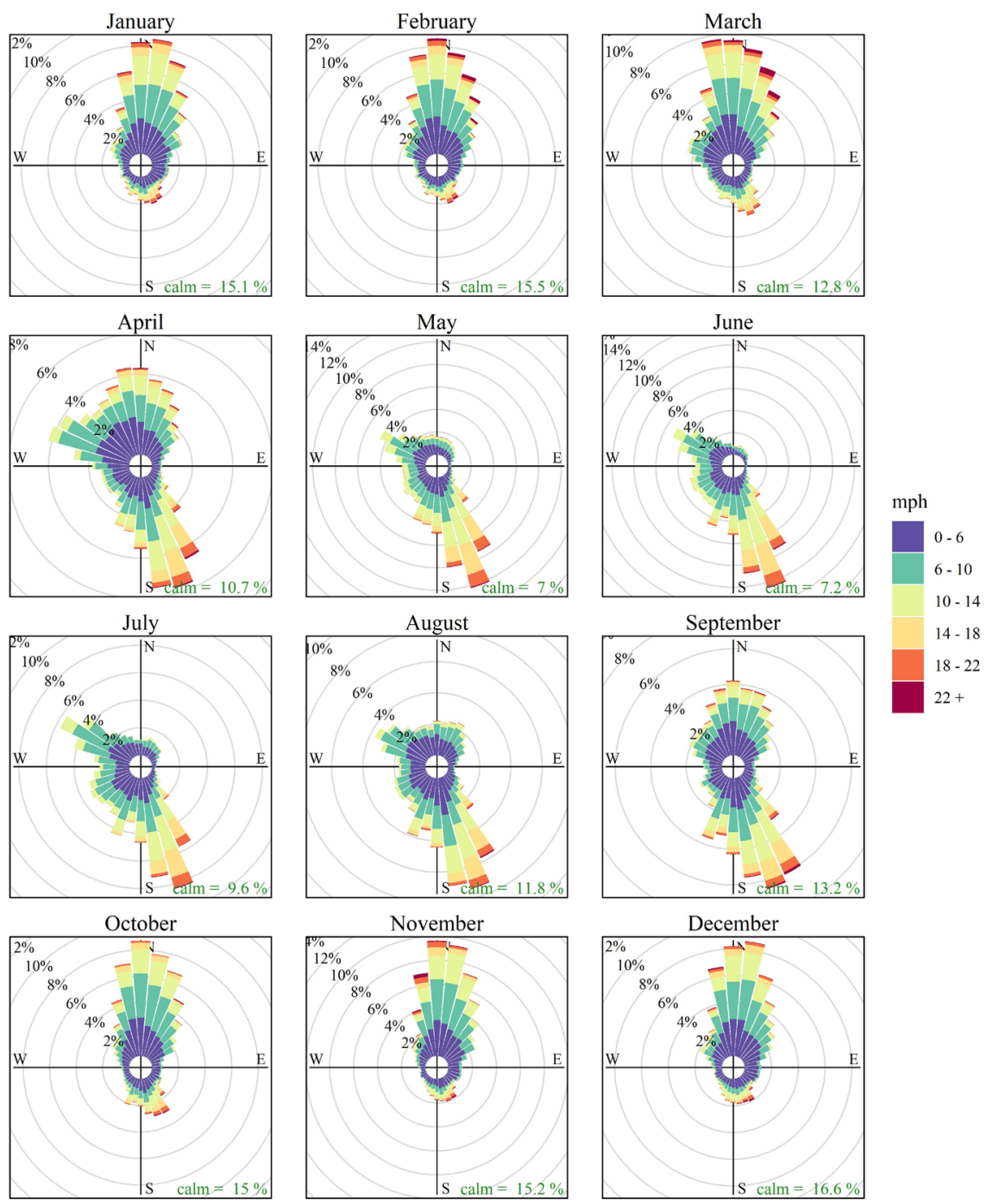

Figure 7. Wind roses showing climatological distributions of wind at Anchorage over the 1980-2014 historical period. A wind rose is shown for each calendar month: January (upper left) through December (bottom right). Spokes point in directions from which wind is blowing; yellow and red shades denote higher speeds. Station wind observations were obtained from Iowa Environmental Mesonet,

https://mesonet.agron.iastate.edu/request/download.phtml.

at coastal locations where wind-driven waves can produce flooding and erosion. Coastal communities in western and northern Alaska are increasingly vulnerable to such events with a reduced ice cover, which results in longer periods without the sea ice buffer that has historically protected these areas during the cold season. [17] document the increasing length of the open water season in this region.

In order to illustrate the seasonal distribution of high-wind events at Alaskan coastal sites, we have used the database of hourly winds to identify events based on prescribed thresholds of wind speed and duration. For each of 8 coastal locations (see Figure 1), a specified threshold of speed (s) must be exceeded for a minimum duration (d) of consecutive hours. The thresholds $s$ and $d$ vary by location. Identification of an event does not allow for "lulls", which are temporary 
drops below the prescribed speed threshold [18]. The thresholds for Barrow (now Utqiagvik), which are identical to those used by [1], resulted in a sample of 18 events over the 1980-2014 historical period when the actual hourly wind observations from Barrow were used. The thresholds for the other locations were chosen to produce similar sample sizes of 10 - 20 events over the 1980-2014 historical period. This strategy of using sample sizes to guide the threshold specification is similar to that used by [19] in a study of coastal storms in western Ireland. Table 2 lists the thresholds by location.

Strong winds near the surface develop in response to strong gradients of sea level pressure. The high-wind events summarized in Table 2 are indeed associated with strong gradients of sea level pressure, although the synoptic pressure patterns that produce the pressure gradients vary widely among the stations. Figure 8 shows composite sea level pressure fields, which are averages of the sea level pressures at the approximate mid-point (in time) of the $\mathrm{n}$ events at each location. For locations on the southern and western coasts, it is apparent that the key feature is a strong extratropical cyclone, identifiable as a center of low pressure. The counter-clockwise circulation around these cyclones explains the predominance of onshore winds during the events at Nome, Juneau and Sitka. At other locations such as Barrow and Kaktovik, the juxtaposition of strong high and low pressure centers is the key feature of the pressure fields. Anchorage is somewhat unique among the eight sites in that its high-wind events are easterly downslope winds on the lee side of the Chugach Mountains; the easterly winds in this case result from a strong south-to-north pressure gradient between high pressure over northern Alaska and a deep low pressure center in the Gulf of Alaska. It should be noted that the strength of the synoptic centers in Figure 8 is dependent on the case-to-case similarity of the pressure patterns. Kaktovik's high-wind events, for example, arose from a relatively diverse set of pressure patterns, so the features of the composite map for Kaktovikare weaker than for the other locations.

Table 2. Thresholds of wind speed (s) and duration (d) used to identify high-wind events over the 1980-2014 historical period. Also shown are the numbers of events meeting these criteria based on the hourly station data, and the percentage of these events in which the wind was predominantly onshore.

\begin{tabular}{|c|c|c|c|c|}
\hline Location & $s$ & d & n (\# of events) & onshore $\%$ \\
\hline Kaktovik & $45 \mathrm{mph}$ & 25 hours & 8 & $25 \%$ \\
\hline Barrow & $30 \mathrm{mph}$ & 20 hours & 18 & $22 \%$ \\
\hline Nome & $30 \mathrm{mph}$ & 10 hours & 15 & $80 \%$ \\
\hline St. Paul & $40 \mathrm{mph}$ & 15 hours & 10 & $100 \%$ \\
\hline Kodiak & $35 \mathrm{mph}$ & 10 hours & 18 & $33 \%$ \\
\hline Anchorage & $25 \mathrm{mph}$ & 10 hours & 16 & $0 \%$ \\
\hline Juneau & $25 \mathrm{mph}$ & 15 hours & 15 & $100 \%$ \\
\hline Sitka & $25 \mathrm{mph}$ & 10 hours & 11 & $100 \%$ \\
\hline
\end{tabular}



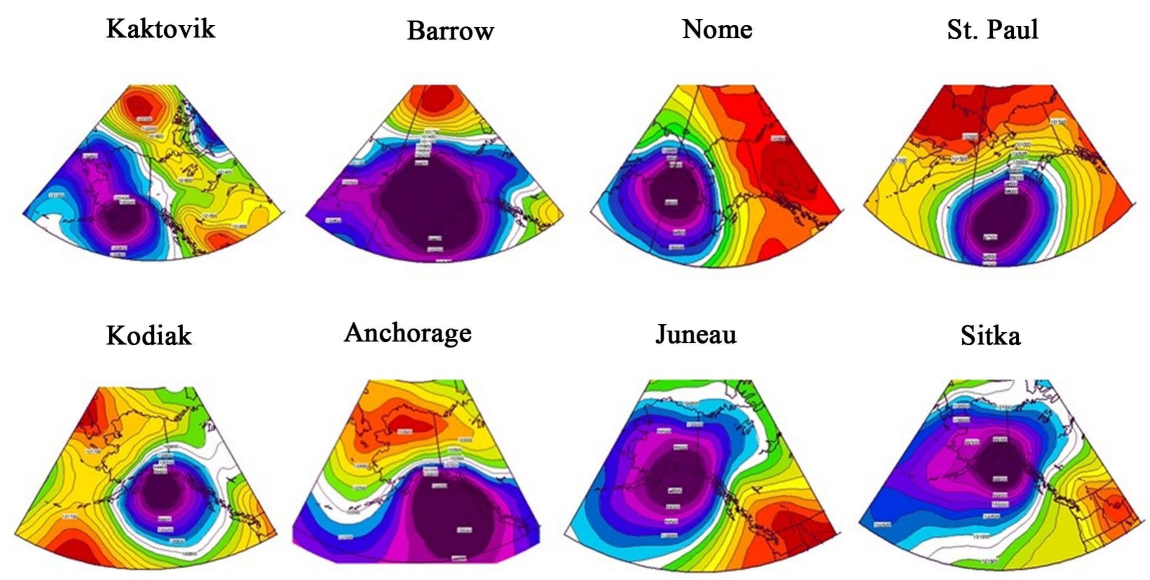

Figure 8. Composite sea level pressure fields for high-wind events at (from upper left to lower right) Kaktovik, Barrow, Nome, St. Paul, Kodiak, Anchorage, Juneau and Sitka. Locations of sites are shown in Figure 1. Data and mapping software from NOAA Earth System Research Laboratory, https://www.esrl.noaa.gov/psd/data/composites/hour/.

The identification of the high-wind events based on station data is hindered by the presence of gaps in the hourly reports. For example, the winds at some stations were occasionally reported at 3-hourly intervals rather than hourly. Even with allowances for missing data by assuming persistence through gaps, it was found that the events based on the hourly station data were under-counted relative to corresponding counts based on the adjusted ERA-driven WRF model simulation of the historical period. For this reason, we base our seasonal climatology of high-wind events on the counts obtained from the historical ERA-driven WRF simulation. Figure 9 illustrates the seasonality of the high-wind events at each site by showing the total numbers of events in the model simulation (based on the thresholds in Table 2) and their distribution by season: winter (Dec-Feb), spring (Mar-May), summer (Jun-Aug) and autumn (Sep-Nov). For the aggregate of the eight sites, high-wind events are most common in winter $(57 \%$ of the total), followed by autumn (28\%) and spring (14\%). However, autumn events account for more than one-third of the annual total at Barrow (43\%), Nome (35\%) and Sitka (36\%). Only about $1 \%$ of the total number of events occur during summer, and no site experiences more than $5 \%$ of its events during summer.

The high-wind events at the eight coastal locations are not evenly distributed through the historical period. As shown in Figure 10, the events were more frequent in the second half than in the first half of the historical period at the northern and western sites (Kaktovik, Barrow and Nome). By contrast, the southern sites (with the exception of Sitka) show decreases over time. The decrease is especially large at Anchorage, where the frequency of events in the first half of the period is nearly twice the frequency in the second half. This tendency for decreasing frequencies in the southern regions and increasing frequencies in the northern regions is consistent with the model projections of future changes, as shown in the following section. 


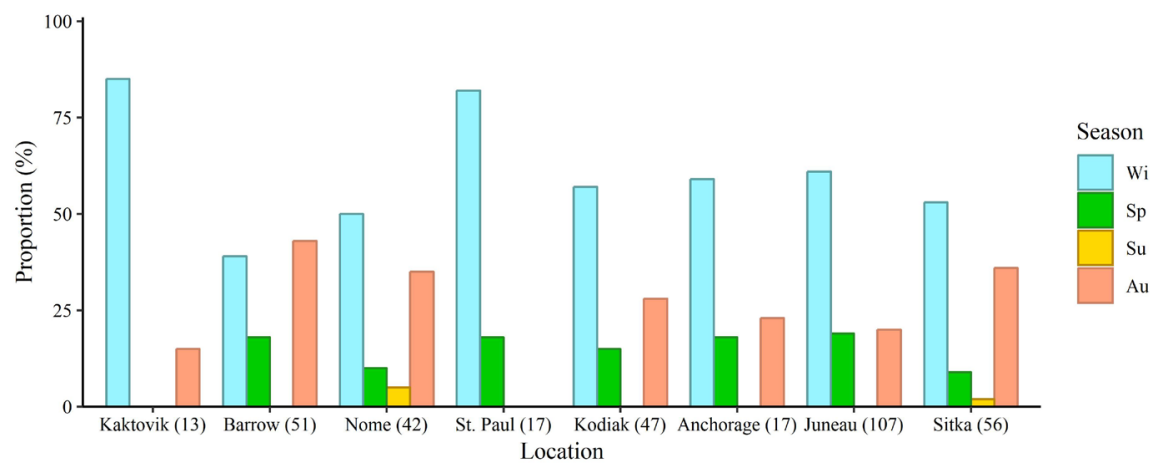

Figure 9. Seasonal distribution (\%) of high-wind events at the eight locations identified in Figure 1. Events are based on the thresholds in Table 2 applied to the ERA-driven WRF model output for the 1980-2014 historical period. Seasons are Winter (Dec-Feb), Spring (Mar-May), Summer (Jun-Aug), Autumn (Sep-Nov).

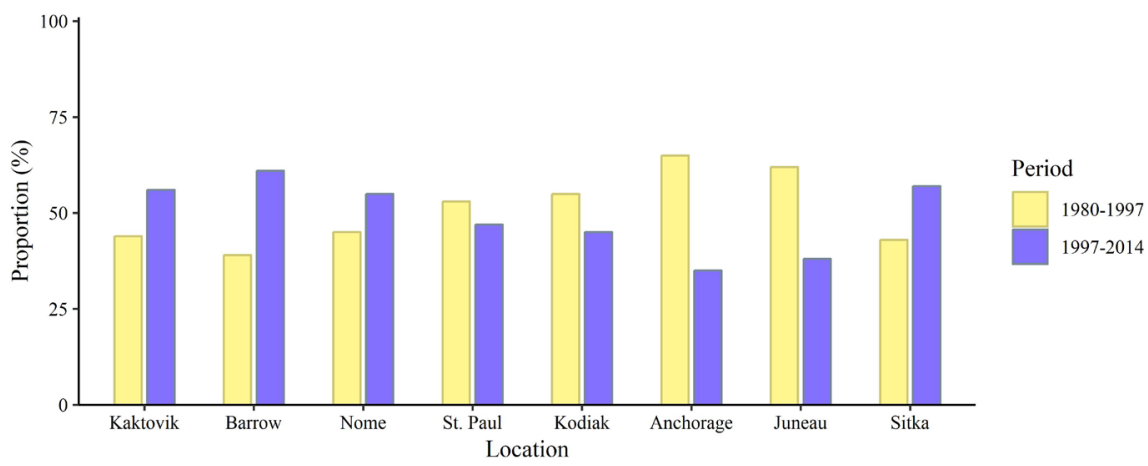

Figure 10. Percentage of high-wind events occurring in first half (left bar) and second half (right bar) of historical period 1980-2014 based on ERA-driven WRF model simulation. Locations of sites are shown in Figure 1.

\subsection{Future Changes}

As summarized in Table 1, simulations spanning the historical and future (through 2100) were carried out with the WRF model driven by boundary conditions from two global climate models (CM3 and CCSM4). In these simulations, the external forcing (greenhouse gas and aerosol concentrations) was prescribed from historical data through 2005 and from the RCP 8.5 scenario from 2006 through 2100. RCP 8.5 represents a "business-as-usual" emission scenario and is at the higher end of the set of four RCP emission scenarios used in the Coupled Model Intercomparison Project, Phase 5 (CMIP5) that informed the IPCC's Fifth Assessment Report [20]. In order to assess future changes in Alaska's wind climatology, we evaluated the mean winds speeds and the frequency of high-wind events by these two model simulations after adjustment to the ERA-forced historical winds as described in Section 2 (Figure 5). The adjusted WRF output obtained from the quantile mapping of both global climate models over both periods was then combined and trimmed to create a historical reference period (1980-2014) and a late-2 $1^{\text {st }}$-century time slice of equal length (2065-2099). 
Differences between the future and historical wind speeds were tested for statistical significance for each calendar month using the output obtained from each global model. Figure 11 shows the spatial and seasonal distributions of the changes that were significant at the $95 \%$ level. Significant positive changes (increases in wind speed) are shaded orange, while significant negative changes (decreases in wind speed) are shaded blue. Several patterns are apparent in Figure 11. First, significant changes are more widespread in the CM3-driven simulation than in the CCSM4-driven simulation. This result is consistent with the known tendency for CM3 to be more sensitive than CCSM4 to external forcing, both globally ([20], their Figure 12.9) and for Alaska ([21]). Second, both models show a similar seasonality in the occurrence of significant changes in winds, with a general tendency for increases during the cold season and decreases in the warm season. The seasonality is much stronger in CM3, but is also detectable in CCSM4. Figure 12 summarizes seasonality of the changes by showing the counts of station-months having significant increases and decreases during

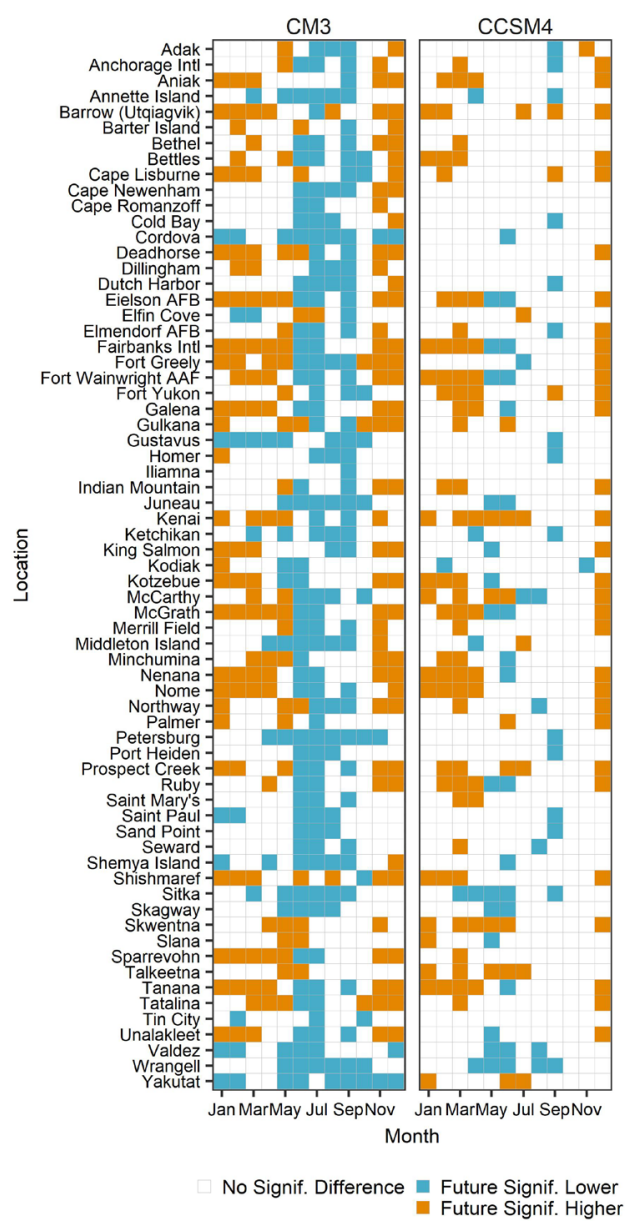

Figure 11. Distribution of statistically significant changes in wind speed from the historical (1980-2014) to the future (2065-2099) time periods. Orange squares denote positive changes, blue squares denote negative changes. Left panel shows changes simulated by CM3 model, right panel changes simulated by the CCSM4 model. In each panel, calendar month ranges from January (left column) to December (right column). 


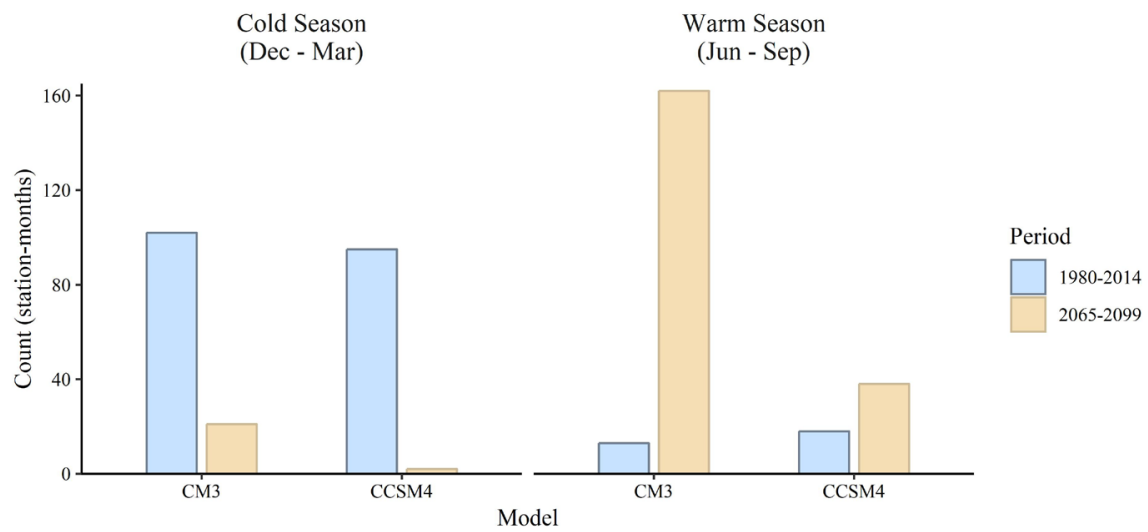

Figure 12. Numbers of station-months with statistically significant trends in wind speed from historical (1980-2014) to future (2065-2099) time periods. Left panel shows number of positive trends (minus number of negative trends) in cold season, December-March. Right panel shows number of negative trends (minus number of positive trends) in warm season, June-September.

the four coldest months (Dec-Mar) and the four warmest months (Jun-Sep). During the cold season, $83 \%$ of CM3's 123 significant changes and $98 \%$ of CCSM4's 97 significant changes are increases. By contrast, during the warm season, 93\% of CM3's 175 significant changes and 68\% of CCSM4's 56 significant changes are decreases. This seasonality has implications for the frequencies of high-wind events (discussed below), which were shown in Section 3.1 to be most common during the cold months.

Finally, there is some regionality inherent in the changes summarized in Figure 11. Increases are most pervasive in the northern and western regions of the state, while the decreases tend to be more common in the southern and southeastern regions. For example, the few stations showing significant decreases during January-March in the CM3 projections include Cordova, Elfin Cove, Gustavus, Ketchikan, Valdez and Yakutat, all of which are in southeastern Alaska, together with St. Paul Island in the southern Bering Sea. This geographical pattern of the projected changes is very similar to the pattern of changes in the observed high-wind events from the historical period (Figure 10), suggesting that the externally forced changes simulated by the models may already be underway.

Given the changes in mean wind speed projected by the two climate models, it is not unreasonable to expect at least some changes in the frequencies of high-wind events. We therefore applied the same threshold criteria used for the eight coastal locations in Section 3.1 to the hourly wind output from the CM3and CCSM4-driven WRF model simulations. Figure 13 summarizes the occurrences of the high-wind events at the eight coastal locations in the historical and future time slices of the two model simulations. For the stations in the south and southeast (St. Paul, Kodiak, Anchorage, Juneau, Sitka), the numbers of high-wind events are similar in the two models, and there is generally little change from the historical to the future periods. However, for Utqiagvik (Barrow) in the 


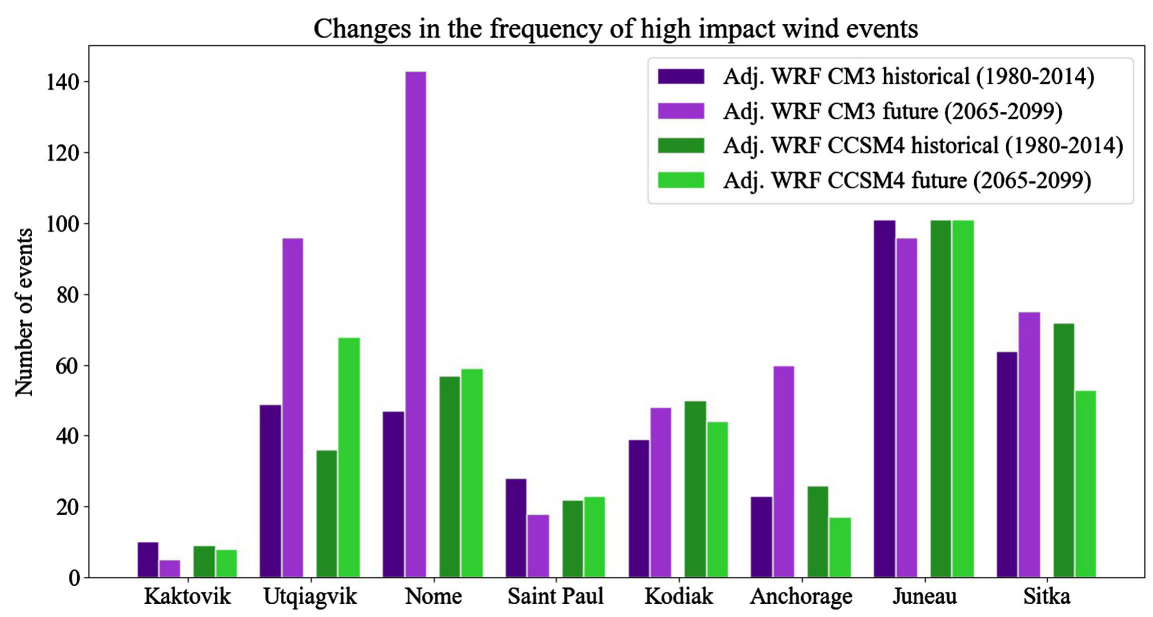

Figure 13. Number of high-wind events in CM3 simulations (purple bars) and CCSM4 (green bars) at eight coastal locations in Figure 1. Darker bars are numbers of events in historical period (1980-2014), lighter bars are numbers of events in future period (2065-2099).

north and Nome in the west, increases in high-wind evens are projected by both models. Consistent with the relative strength of the overall signal in mean wind speed, the changes are stronger in CM3 than in CCSM4. The projected increases are large, approximately a doubling in frequency from the historical to the future, at Utqiagvik (Barrow) in both models. The CM3 model projects a tripling of highwind events at Nome, although CCSM4 projects only a small increase. Interestingly, the numbers of events at Kaktovik on the northeastern coast are the smallest of all eight sites in both models in both the historical and future time periods.

Given the prominence of storms in the pressure patterns associated with high-wind events (Figure 8), the changes in high-wind events can be interpreted in terms of shifts in storm tracks. The fact that the northern and western coastal sites are projected to experience more frequent events suggests an increase in storms in this region, especially during the autumn and winter seasons when the events are most frequent. At least some climate models have shown tendencies for northward shifts of storm tracks in the North Pacific sector under climate warming scenarios [22], and there is some evidence that storm tracks have already undergone such shifts in recent decades [23]. There is also the likelihood that increases in the fluxes of latent and sensible heat will increase storm intensity in areas of diminished sea ice, as will be (and already is) the case in the Bering and Chukchi Seas offshore of Nome and Barrow, respectively. The geographical variation of the changes in high-wind event frequency in Figure 13 indeed implicates sea ice as a contributing factor through impacts on storms.

Regardless of the physical and dynamical mechanisms responsible for the changes in high-wind events, the results in Figure 13 have implications for coastal communities of western Alaska. Because the vulnerability to coastal flooding and erosion is much greater when sea ice is not present to buffer the coastline, the coastal sectors encompassing Nome and Barrow are increasingly 
vulnerable under the present recession of sea ice, even in the absence of any changes in high-wind events. The projected increases in such events compounds the risks to these coastal sectors, pointing to the need for planning and adaptation actions by coastal communities in the region.

\section{Conclusions}

The use of hourly winds from surface stations and from the downscaling of climate model simulations has permitted a synthesis of wind information for Alaska. To our knowledge, this is the first wind climatology for Alaska to make use of both quality-controlled station measurements and bias-adjusted model output. The examples presented here show that the surface observations are replicated closely by the winds downscaled from a reanalysis-driven model simulation. While the station observations effectively calibrate the model output, the model output fills in the missing data in the station reports.

The wind climatology provides information on the geographical and seasonal variations of winds in Alaska. Winds are generally stronger at coastal and offshore (island) locations than at interior sites. The season of peak wind speed varies from winter in the coastal and offshore locations to summer in interior areas, where calm conditions are frequent in winter. Many sites also show strong seasonality in the prevailing wind direction. The hourly data allow the evaluation of high-wind events, which are especially consequential in coastal areas. Not only are the winds stronger during coastal high-wind events than during inland high-wind events, but coastal flooding and erosion represent hazards unique to coastal areas. Throughout the coastal regions, high-wind events are most frequent in the cold season. Over the historical period spanning 1980-2014, there has been an increase in the frequency of these events in the northern and western coastal region, with no systematic change in other coastal sectors.

The data-model fusion framework enabled us to evaluate downscaled future projections driven by two different climate models. The changes by the late $21^{\text {st }}$-century are statistically significant at many locations, and their seasonality is qualitatively similar in the two models: an increase of mean wind speeds in the cold season and a decrease of mean wind speeds in the warm season. The signal is stronger in the simulation driven by the GFDL CM3 model than in the CCSM4-driven simulation. High-wind events are projected by both models to become more frequent in the northern and western Alaska coastal regions, which are precisely the regions in which the protective sea ice cover has been diminishing (a trend that is projected to continue), pointing to increased risks of coastal flooding and erosion. The extent to which these future changes are attributable to changes in storm tracks, storm frequencies or storm intensity is a subject of future work.

\section{Funding}

This work was supported by the National Science Foundation through Grant 
ARC-1602720 and by the National Oceanic and Atmospheric Administration's Climate Program Office through Grant NA16OAR4310162. Sarah T. Pearl was funded through the REU (Research Experience for Undergraduates) program of the National Science Foundation under Grant ARC-1560372.

\section{Conflicts of Interest}

The authors declare no conflicts of interest regarding the publication of this paper.

\section{References}

[1] Lynch, A.H., Curry, J.A., Brunner, R.D. and Maslanik, J.A. (2004) Toward an Integrated Assessment of the Impacts of Extreme Wind Events on Barrow, Alaska. Bulletin of the American Meteorological Society, 85, 209-222. https://doi.org/10.1175/BAMS-85-2-209

[2] Hughes, M. and Cassano, J.J. (2015) The Climatological Distribution of Extreme Arctic Winds and Implications for Ocean and Sea Ice Processes. Journal of Geophysical Research, 120, 7358-7377. https://doi.org/10.1002/2015JD023189

[3] Stegall, S.T. and Zhang, J. (2012) Wind Field Climatology, Changes and Extremes in the Chukchi-Beaufort Seas and Alaska North Slope during 1979-2009. Journal of Climate, 25, 8075-8089. https://doi.org/10.1175/JCLI-D-11-00532.1

[4] Saha, S., et al. (2010) The NCEP Climate System Forecast Reanalysis. Bulletin of the American Meteorological Society, 91, 1015-1057. https://doi.org/10.1175/2010BAMS3001.1

[5] Hundecha, Y., St-Hilaire, A., Quarda, T.B.M.J., El Adlouni, S. and Gachon, P. (2008) A Nonstationary Extreme Value Analysis for the Assessment of Changes in Extreme Wind Speed over the Gulf of St. Lawrence, Canada. Journal of Geophysical Research, 117, D18116. https://doi.org/10.1175/2008JAMC1665.1

[6] Wan, H., Wang, X.L. and Swail, V.R. (2010) Homogenization and Trend Analysis of Canadian Near-Surface Wind Speeds. Journal of Climate, 23, 1209-1225. https://doi.org/10.1175/2009JCLI3200.1

[7] Kramm, G., Mölders, N., Cooney, J. and Dlugi, R. (2019) Near-Surface Wind-Speed Stilling in Alaska during 1984-2016 and Its Impact on the Sustainability of Wind Power. J. Power and Energy Engineering, 7, 71-124. https://doi.org/10.4236/jpee.2019.77006

[8] Pryor, S.C., Barthelmie, R.J. and Schoof, J.T. (2012) Past and Future Wind Climate over the Contiguous USA Based on the North American Regional Climate Change Assessment Program Model Suite. Journal of Geophysical Research, 117, D19119. https://doi.org/10.1029/2012JD017449

[9] Mölders, N., Khordakova, D., Dlugi, R. and Kramm, G. (2016) Sustainability of Wind Energy under Changing Wind Regimes-A Case Study. Atmospheric and Climate Sciences, 6, 158-173. https://doi.org/10.4236/acs.2016.62014

[10] Skamarock, W.C., et al. (2008) A Description of the Advanced Research WRF Version 3. NCAR Tech Note, NCAR/TN-475+STR, $113 \mathrm{p}$.

[11] Zhang, X., Zhang, J., Krieger, J. and Shulski, M. (2013) Final Project Report for the Beaufort and Chukchi Seas Mesoscale Meteorology Modeling Study. Bureau of Ocean Energy Management, 4 p. http://www.data.boem.gov/PI/PDFImages/ESPIS/5/5301.pdf 
[12] Dee, D.P., et al. (2011) The ERA-Interim Reanalysis: Configuration and Performance of the Data Assimilation System. Quarterly Journal of the Royal Meteorological Society, 137, 553-597. https://doi.org/10.1002/qj.828

[13] Bieniek, P.A., Bhatt, U.S., Walsh, J.E., Rupp, T.S., Zhang, J., Kreiger, J.R. and Lader, R. (2016) Dynamical Downscaling of ERA-Interim Temperature and Precipitation for Alaska. Journal of Applied Meteorology and Climatology, 55, 635-654. https://doi.org/10.1175/JAMC-D-15-0153.1

[14] Lader, R., Bhatt, U.S., Walsh, J.E., Rupp, T.S. and Bieniek, P.A. (2016) Two-Meter Temperature and Precipitation from Atmospheric Reanalysis Evaluated for Alaska. Journal of Applied Meteorology and Climatology, 55, 901-922. https://doi.org/10.1175/JAMC-D-15-0162.1

[15] Lader, R., Walsh, J.E., Bhatt, U.S. and Bieniek, P.A. (2017) Projections of Twenty-First Century Climate Extremes for Alaska via Dynamical Downscaling and Quantile Mapping. Journal of Applied Meteorology and Climatology, 56, 2393 2409. https://doi.org/10.1175/JAMC-D-16-0415.1

[16] Walsh, J.E., Bhatt, U.S., Littell, J.S., Leonawicz, M., Lindgren, M., Kurkowski, T.A., Bieniek, P.A., Thoman, R., Gray, S. and Rupp, T.S. (2018) Downscaling of Climate Model Output for Alaska Stakeholders. Environmental Modelling and Software, 110, 38-51. https://doi.org/10.1016/j.envsoft.2018.03.021

[17] Rolph, R.J., Mahoney, A.R., Walsh, J. and Loring, P.A. (2018) Impacts of a Lengthening Open Water Season on Alaskan Coastal Communities: Deriving Locally Relevant Indices from Large-Scale Datasets and Community Observations. The Cryosphere, 12, 1779-1790. https://doi.org/10.5194/tc-12-1779-2018

[18] Atkinson, D.A. (2005) Observed Storminess Patterns and Trends in the Circum-Arctic Coastal Regime. Geo-Marine Letters, 25, 98-109.

https://doi.org/10.1007/s00367-004-0191-0

[19] MacClenahan, P., McKenna, J., Cooper, J.A.G. and O’Kane, B. (2001) Identification of Highest Magnitude Coastal Storm Events over Western Ireland on the Basis of Wind Speed and Duration Thresholds. International Journal of Climatology, 21, 829-842. https://doi.org/10.1002/joc.666

[20] Collins, M., Knutti, R., Arblaster, J., Dufresne, J.-L., Fichefet, T., Friedlingstein, P., Gao, X., Gutowski, W.J., Johns, T., Krinner, G., Shongwe, M., Tebaldi, C., Weaver, A.J. and Wehner, A.J. (2013) Long-Term Climate Change: Projections, Commitments and Irreversibility. In: Stocker, T.F., Qin, D., Plattner, G.-K., Tignor, M., Allen, S.K., Boschung, J., Nauels, A., Xia, Y., Bex, V. and Midgley, P.M., Eds., Climate Change 2013: The Physical Science Basis. Contribution of Working Group I to the Fifth Assessment Report of the Intergovernmental Panel on Climate Change, Cambridge University Press, Cambridge, United Kingdom and New York, 1585 p.

[21] Lader, R., Walsh, J.E., Bhatt, U.S. and Bieniek, P.A. (2019) Agro-Climate Projections for a Warming Alaska. Earth Interactions, 22, 1-24.

https://doi.org/10.1175/EI-D-17-0036.1

[22] Knudsen, E.M. and Walsh, J.E. (2016) Evaluation of Northern Hemisphere Storminess in the Norwegian Earth System Model. Geoscientific Model Development, 9, 2335-2555. https://doi.org/10.5194/gmd-9-2335-2016

[23] Wang, X.L., Feng, Y., Compo, G., Swail, V., Zwiers, F., Allan, R. and Sardeshmukh, P. (2012) Trends and Low Frequency Variability of Extra-Tropical Cyclone Activity in the Ensemble of Twentieth Century Reanalysis. Climate Dynamics, 40, 2775 2800. https://doi.org/10.1007/s00382-012-1450-9 